\title{
Erratum: Toward Lossless Infrared Optical Trapping of Small Nanoparticles Using Nonradiative Anapole Modes [Phys. Rev. Lett. 127, 186803 (2021)]
}

\author{
J. J. Hernández-Sarria, Osvaldo N. Oliveira, Jr., and J. R. Mejía-Salazar
}

@ (Received 6 December 2021; published 27 December 2021)

DOI: 10.1103/PhysRevLett.127.279901

Just after this Letter was available online it was brought to our attention a Ref. [1] that is closely related to the subject of this work. With this Erratum we wish to mention the authors of the related study.

[1] A. M. Jazayeri and K. Mehrany, All-dielectric structure for trapping nanoparticles via light funneling and nanofocusing, J. Opt. Soc. Am. B 34, 2179 (2017). 